Review Paper:

\title{
A Review Study of Diaper Rash Dermatitis Treatments
}

\author{
Zahra Sharifi-Heris $^{1} \oplus$, Leila Amiri Farahani ${ }^{1 *} \oplus$, Seyede Batool Hasanpoor-Azghadi ${ }^{1}$
}

1. Department of Midwifery and Reproductive Health, School of Nursing and Midwifery, Iran University of Medical Sciences, Tehran, Iran.

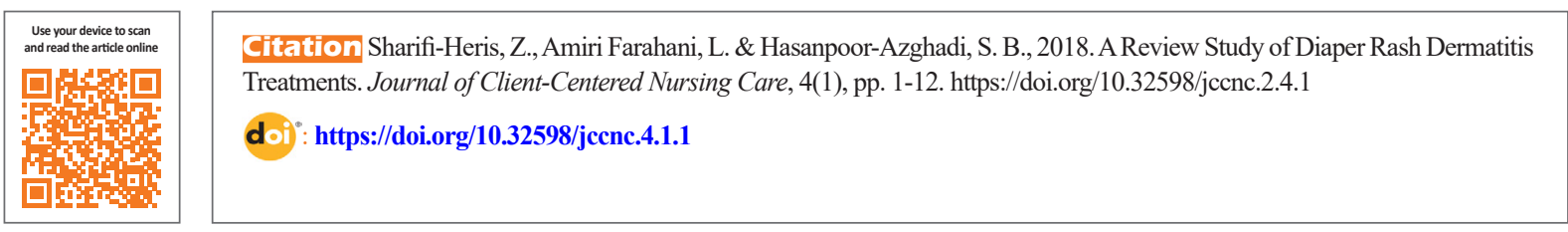

Funding: See Page 8

(c) Copyright: The Author(s)

Article info:

Received: 10 Jul 2017

Accepted: 20 Nov 2017

Available Online: 01 Feb 2018

Keywords:

Diaper dermatitis,

Traditional medicine,

Chemical medicine,

Complementary therapy,

Alternative medicine

\begin{abstract}
A B S T RA C T
Background: Inflammation caused by diapers is one of the most common skin diseases in infants and children all over the world. Among the current therapies, modern chemical medicines are the most common ways of therapy despite their potential risks. In the present study, a variety of available chemical and complementary therapies are presented to facilitate the selection or further research on the range of available treatments with no or fewer side effects.

Methods: Published articles on diaper dermatitis were searched in databases and search engines, including Magiran, Irandoc, SID, Ovid, PubMed, Google Scholar, ScienceDirect, and IranMedex from 2010 to 2018. Finally, a total of 80 articles out of the 138 related articles were reviewed.

Results: The treatments were divided into two general categories of topical and systemic treatments. Topical treatments included chemical and herbal subcategories. Corticosteroids, antibacterial agents, antifungals, and other medications composed chemical treatments. According to the information obtained from each category, corticosteroids are the most risky and herbal medicine the safest medication. However, herbal and traditional medicines were the most widely-used treatments for diaper dermatitis.
\end{abstract}

Conclusion: According to the findings, the choice of appropriate prescription and safe treatment for medical personnel and parents of children is limited. Further studies are recommended on traditional medicines that little information is available about them.

\section{Background}

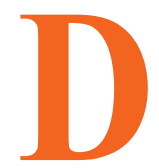

iaper rash dermatitis refers to a group of skin disorders characterized by acute inflammatory reaction (regardless of the cause) on diaper covered area caused by physical, chemical, enzymatic, and microbial agents (Visscher et al. 2015). It is one of the most common skin diseases in infants and children and develops at least once during the use of diapers (Blume-Peytavi et al. 2014). Its global prevalence is between $7 \%$ and $35 \%$ and even in some studies up to $50 \%$. In the United States, diapers dermatitis constitutes $10 \%$ to $20 \%$ of all skin disorders (Horii 2017).

In Iran, $20 \%$ of healthy children are prone to this disease (Zitás \& Mészáros 2017). The consequent rash causes restlessness, insufficient breastfeeding, and in-

\section{* Corresponding Author:}

Leila Amiri Farahani, PhD

Address: Department of Midwifery and Reproductive Health, School of Nursing and Midwifery, Iran University of Medical Sciences, Tehran, Iran. Tel: +98 (21) 43651139

E-mail: amirifarahani.l@iums.ac.ir 
somnia in infants, and over-anxiety in parents (Kuller 2016). The inflammation is the cause of $25 \%$ of referrals to physicians and pediatricians (Hockenberry \& Wilson 2014). This disorder is usually seen from the $3^{\text {rd }}$ to the $12^{\text {th }}$ weeks of age, and its peak is at the age of 6-12 months (Carvalho et al. 2015).

The rash can seriously involve the skin and cause microbial infections with normal skin flora such as streptococcus or fungus, and if untreated, it may turn into skin ulcer and secondary infections. The infection may cause adhesion and scars in the genital area which consequently requires operation (Srivastava \& Gupta 2015).

The choice of treatment among a host of different treatments is undoubtedly an obsession for many parents and care givers of children and even the health staff. Neglecting such cases may create serious threats to human health, especially with many over the counter medications (Stamatas \& Tierney 2014). Diaper dermatitis is counted as those problems for which parents do not usually refer to clinics and instead seek selfmedication (Blume-Peytavi et al. 2014).

Self-administered treatment without knowledge about drug profiles and subsequent complications can affect the child's health and the community. In health centers, the choice of the treatment is mainly based on the preference of the medical staff (Stamatas \& Tierney 2014), while choosing a treatment should be based on faster treatment with minimal complications (Visscher et al. 2015).

Unfortunately, the available treatments, regardless of their effects and complications might fail to accomplish the goals, so create challenges and limitations in choosing the type of treatment (Blume-Peytavi et al. 2014). In light of these issues, the present study aimed to collect the required information to review the drugs used in diaper dermatitis, and find safer and more effective medicine.

\section{Materials and Methods}

This is a review study; the information was collected by reviewing various national and international articles on the treatment of diaper dermatitis, as well as articles on traditional medicine and pediatric care. The terms "diaper dermatitis" and "diaper rash" were used to search for the diaper area inflammation. The keywords "treatment of diaper dermatitis in infants", "treatment of diaper rash in infants", and "traditional medicine" were searched in databases and search engines such as Magiran, Iran doc, SID, Ovid, PubMed, Google Scholar ScienceDirect, and IranMedex between 2010 and 2018. In the end, a total of 138 related articles were found. After reviewing the articles, 80 more related articles were selected and 38 other articles were removed. The related articles were studied and the obtained data were categorized.

\section{Results}

Based on the obtained information, different treatments were divided into topical and systemic treatments. Topical treatments are divided into two categories of chemical therapies (modern medicine) and herbal treatments. The category of chemical therapies included corticosteroids, antibacterial and antifungal agents as well as various medicines. Some information such as drug category, their efficacy, side effects and directions for proper use was tried to be included in each drug. Selecting a treatment for children with dermatitis depends on the age, amount of inflammation, involvement with secondary infection, and underlying diseases (Stamatas \& Tierney 2014).

\section{Topical treatments}

Topical treatments include herbal medicine, topical corticosteroids, antifungals, antibacterials and other topical skin medications (Mack 2010). In newborns, the absorption and potency of drugs increase due to the proportion of body surface to its volume (Mack 2010) and the presence of humidity and closure of the diaper environment, resulting in higher exposure to topical drugs (Telofski et al. 2012). As a result, in selecting a drug, factors such as its systemic absorption, duration of action, penetration, solubility, chemical stability, and hydration of stratum corneum should be brought to attention (Mooney et al. 2015).

Topical compounds are often selected based on the physician's preferences and experience. There is no precise information on the onset, peak, and duration of the effect regarding the drugs (Shenton et al. 2012; Liu et al. 2013). A desirable topical compound should include a wide range of features, including effective activity against the infecting organism, ability to penetrate deeply into the lesion, its ease of use, without pain and toxic effects, no systemic malabsorption, long-lasting effect, and easy and inexpensive access (Tan et al. 2012). 


\section{Chemical drugs (modern medicine)}

Chemical drugs usually act faster than herbal medicines, but long periods of use or in some cases their intermittent use may leave side effects more dangerous than the disease itself (Swain et al. 2018). Persistent, excessive, and incorrect use of chemical drugs may create resistance to these drugs (Shenton et al. 2012).

\section{Corticosteroid}

Topical glucocorticoids play a crucial role in the treatment of inflammatory diseases (Jungersted et al. 2011). Anti-inflammatory and anti-proliferative effects of topical corticosteroids are the reasons for their effectiveness on the skin; however, their long-term and inappropriate use cause topical (skin atrophy, abnormal pigmentation, exacerbation of fungal infections, telangiectasia, striae, etc.) and systemic side effects (suppression of hypothalamic-pituitary-adrenal-axis, Cushing syndrome, retardation and growth retardation in children) due to suppression of the immune system (Jungersted et al. 2011).

Ointment-based topical steroids show better effects due to their intrinsic coating and moisture enhancement in comparison to lotion and cream carriers (Liu et al. 2013). In recent years, an increasing trend in the steroidal disorders has been observed due to the systemic complications of the steroids (Jungersted et al. 2011). Medium and high potent corticosteroids should not be used to treat diaper dermatitis in infants (Mirshad et al. 2017). The frequency of corticosteroid use is at least twice a day and should not be used for longer than 2 weeks. Corticosteroids can cause irreparable side effects in terms of their form and percentage of the drug (Merrill 2015; Klunk, Domingues \& Wiss 2014).

Hydrocortisone ointment acts as an anti-inflammatory compound (alone or in combination with some antibiotics or topical antifungals) and generally has fewer side effects compared to other anti-inflammatory drugs. Hydrocortisone cream with $0.2 \%, 0.5 \%$, and $1 \%$ concentration is used in the diaper area. It must be applied to the skin immediately if it is used simultaneously with other types of burn creams; however, short-term use of this drug does not usually have a specific complication (Rasu et al. 2013). In children over 2 years of age, it should not be used more than 2 times a day and longer than 7-10 days unless prescribed by a physician. Its dose in children younger than 2 years has not been determined yet (McQuestion 2011).
Desonide $0.05 \%$ is a modified and non-halogenated hydrocortisone with low strength. It is a safe and effective drug in treating mild to moderate skin inflammation, especially in children with sensitive skin. Like other topical steroids, it has anti-inflammatory and anti-irritant properties (Basha et al. 2015), but unlike most topical steroids, both cream and lotion forms are equally potent and effective (Babu, Rao \& Rao 2014). Desonide cream $0.05 \%$ is safer than hydrocortisone $1 \%$ and no signs of atrophy have been observed after its use. Long-term use of this agent (usually longer than a week) causes thinning and cracking of the skin (Inakanti et al. 2015).

Triamcinolone is a moderate strength glucocorticoid with anti-inflammatory and immunosuppressive effects. The drug is five times stronger than hydrocortisone (with equivalent weight) (Delgado-Charro \& Guy 2014). Cream $0.1 \%$ and ointment of this drug is prescribed to treat skin infections, such as dermatitis. Impairment in child development and thinning of the skin after prolonged use as well as allergies are probable. The frequency of consumption in a child is 1-2 times a day and should not be continued longer than two weeks (Eichenfield et al. 2014).

Betamethasone is classified in the category of strong topical corticosteroids and is available as ointment and lotion $0.05 \%$ and cream $0.1 \%$. Betamethasone is used to treat symptoms of dermatitis and other skin inflammations which do not respond to other weak corticosteroids (Zannolli et al. 2012). The skin metabolism of this drug is slower than other topical corticosteroids; therefore, its repeated prescription leads to accumulation of the drug in the skin and can prolong the duration of its effect, exacerbation of side effects, and increased systemic drug absorption. Generally it is not suitable for children and should not be used more than once a day (Jungersted et al. 2011).

\section{Antibacterial drugs}

Antibacterial therapy with topical antibiotics should be added when there is a suspicion of bacterial infection. These drugs are usually used 2-3 times a day and should not be used longer than 10 days. If no improvement occurs, oral antibiotics which are effective against staphylococci (cephalexin) and streptococci (penicillin macrolides for those allergic to penicillin) are recommended (Oranje 2015). When staphylococcus is resistant to penicillin, treatment with triamcinolone, sulfamethoxazole or clindamycin should be considered (Heng et al. 2013). 
Retapamulin is categorized with clindamycin and mupirocin. It was approved by the Food and Drug Administration (FDA) in 2007. It affects immediately with low doses (Dhingra, Parakh \& Ramachandran 2013); systemic side effects are low in topical application (Moody, Morrison \& Tyring 2010). Side effects occur rarely and more often in the form of irritation. It is used in children older than 9 months (Weinberg \& Tyring 2010).

Bacitracin (polysoprin) is a bactericide antibiotic with limited activity and little topical absorption, and is used with or without prescription in skin infections with mild Gram-negative bacteria and most Gram-positive bacteria such as staphylococci. It is often used in combination with other topical agents (Schwartz \& Mutairi 2010). It does not generate serious side effects and has no systemic absorption, but some cases of severe dermatitis have been reported. It is often prescribed in the United States and Canada. The drug is usually used 2-3 times a day until complete recovery (Weinberg \& Tyring 2010).

Mupirocin is an effective topical antibiotic against skin infections with Gram-positive bacteria and staphylococcus aureus resistant to treatment (O'Dennell, Gelone \& Safdar 2014). It is prohibited to be used over mucous membrane (Bode et al. 2010). Due to increasing concerns regarding drug resistance, use of longer than 10 days is not recommended (Kharazmi et al. 2012). Common side effects include contact dermatitis (O’Dennell, Gelone \& Safdar 2014), pruritus and rash at the site of use, headache and nausea. Long-term use may lead to the increase of fungal growth (Kharazmi et al. 2012). The mechanism of mupirocin action is different from other antibiotics and it works by stopping the protein to the bacteria which usually causes the death of the bacteria (Bode et al. 2010).

\section{Antifungals}

Over the past two decades, fungal infections have significantly increased (Qian et al. 2012). Despite the remarkable advances in diagnostic methods and antifungal drug research over the past 10 years, the problem of early diagnosis is a major challenge due to the complexity of the patients' clinical profiles and consequently increased invasive activity of the fungi (Rani et al. 2013). Potential side effects of antifungal drugs are allergic reactions such as burning and itchy sensation (Hoeger, Stark \& Jost 2010).

Nystatin is the most common topical drug used in the prevention and treatment of yeast-derived skin infec- tions (Bodin, Godoy \& Philips 2015). It is applied to reduce the invasive fungal infections in very low-weight infants $(<1500 \mathrm{~g})$, although fluconazole is preferable in such cases (Ban \& Tan 2010). In the UK, use of nystatin is limited to patients over one month. Common side effects during topical use include burning, itching, rash, and severe dermatitis (Iammatteo et al. 2017). It does not have catastrophic effects on animals and plants (Bodin, Godoy \& Philips 2015). The duration of treatment is 7-10 days and several times a day, which is reduced to twice daily in combination with triamcinolone (Liu et al. 2011).

Clotrimazole is a broad-spectrum topical antifungal drug used in the treatment of various types of fungal infections. Clotrimazole stops fungus growth by preventing cell proliferation, but could also be fatal for the fungus due to the amount of usage (Crowley \& Gallagher 2014). Systemic absorption of this drug is low after skin intake. Side effects of Clotrimazole are very rare. The antifungal effect of Clotrimazole is more than nystatin and it is not recommended for children under the age of two (Hoeger, Stark \& Jost 2010).

Miconazole nitrate $2 \%$ cream is used for skin fungal infections. Its mechanism of action is the same as nystatin (Tamblyn et al. 2012). In children over one month old, nystatin can be a good alternative. Unlike nystatin, miconazole (oral or topical) may interfere with anticoagulant drugs (Segura-Bedmar, Martinez \& Pablo-Sánchez 2011). In Candida dermatitis, the drug is prescribed in the diaper area for children over 4 weeks after each diaper change for up to 7 days. The safety of the drug in children under one year old is unclear. Preventive use may lead to drug resistance (Rai et al. 2014). Drug resistance to miconazole has not been reported in long-term use (Blanco \& Rossem 2013).

Ketoconazole and econazole nitrate are both antifungal imidazole, which are now used less due to the replacement by more effective and safer treatments (Verma \& Pathak 2012). It is worth mentioning that the gel form of this drug has a remarkable potential for treatment as a topical agent due to controlled release of the drug, better antifungal activity, and good storage stability (Verma \& Pathak 2012).

Ciclopirox is an antifungal topical drug with antimicrobial activity. It is topically used in the treatment of skin and fungal infections in the form of cream, gel, lotion, solution or powder, and is mostly used as ciclopirox olamine $1 \%$ twice daily. Itching and burning have been reported after topical use of this drug. Two 
blind studies have demonstrated that it is more effective than clotrimazole and has the same general profile and side effects (Shen \& Huang 2016).

\section{Other drugs}

Triamcinolone N.N is a combination of triamcinolone (corticosteroid), nystatin (antifungal), and neomycin (antibacterial). This drug has less skin metabolism, and therefore the systemic absorption of the drug is relatively high, resulting in a high probability of systemic complications (Anthony 2016). It is usually used twice a day, and the use of this combination is only justifiable for short-term treatment (less than two weeks) of skin inflammation associated with bacterial infection or candidiasis. Sensitization and skin thinning are not unexpected after prolonged use (Al-Faraidy \& Al-Natour 2010).

Zinc oxide has nearly zero solubility in water and mild anti-inflammatory, anti-irritant, regenerative, and moisturizing effect (Mack 2010). This ointment acts as a physical barrier to water absorption, and by inhibiting the adhesion and penetration of microorganisms, reduces bacterial infections in mild dermatitis (Gupta et al. 2014). It has no serious side effects. Zinc oxide ointment $5 \%$ can be used to reduce the symptoms of diarrheainduced diaper dermatitis (Bae et al. 2010). Zinc oxide produces antiperspirant properties in the diaper area in combination with potassium and it is used as a topical treatment for dermatitis in children in combination with glycerin (Del val, kontoravdi \& Nagy 2010). Ideally, it is used after each diaper change (Bae et al. 2010).

Ointment for vitamins (A, D, D3) contains the most essential vitamins needed for the skin and is used as a preventive and therapeutic agent for skin protection and recovery of mild inflammation in the areas of the infant's skin which is in contact with urine and stool (Christensen et al. 2017). It has moisturizing, antimicrobial, and antiirritation properties with little fat. It is well absorbed and easily washed off and available in $30 \mathrm{~g}$ tubes ointment and cream. It is used as needed and usually after each diaper change (Merrill 2015). Each gram of ointment contains 850 units of Vitamin A and 85 units of Vitamin D in the oily base (Christensen et al. 2017).

Dexpanthenol is a derivative of pantothenic acid (Vitamin B5) and its $0.1 \%$ to $0.5 \%$ ointment is used in children. It is rapidly absorbed through the skin and accelerates wound healing and relieves itching by stimulating epithelization and granulation (Camargo, Gaspar \& Maia Campos 2011). It also acts as a moisturizer and helps maintaining the softness and elasticity of the skin.
It also has a protective effect against inflammation in the diaper area by reducing skin hydration. Itching, red spots, dermatitis, and skin irritation may appear as its side effects (Heise et al. 2012). The dosage is usually 1-2 times a day depending on the needs of the child and the doctor's preference (Rai et al. 2014).

Petrolatum (petroleum jelly, paraffin gel) is a nonodorous combination of refined semi-solid hydrocarbons used in many primary bases of children creams and lotions. It has moisturizing, coating, protective and wound healing properties, and is considered as one of the most common preventive and therapeutic agents in diaper dermatitis (Speight 2014). It also has mediumrisk safety rating. According to Perl Gibson, Calgary Pharmacist, petrolatum deprives skin of water and oxygen, causing damage to the skin. It is usually used as an obstructive barrier in the preparation of topical agents used for the skin (Panahi et al. 2012) and there is no usage restriction as well (Speight 2014).

\section{Herbal medicines}

The use of herbal medicines on the skin of children has a long history in many parts of the world; however, their composition, oxidation, light sensitivity and biological activity vary on different surfaces (Blume-Peytavi et al. 2014). The use of medicinal plants as antibacterial and anti-inflammatory drugs is common in Iranian general medicine, and no significant adverse effects have been reported (Panahi et al. 2012); nevertheless, the probability of contact dermatitis have been reported in most of them (Reider \& Fritsch 2012; Macias et al. 2014). In most cases, the treatment duration is 7-10 days at least 3 times a day or after each diaper change when necessary and according to the doctor's preferences (Panahi et al. 2012; Srivastava \& Gupta 2015).

\section{Calendula}

Calendula ointment is a non-steroidal anti-inflammatory drug used in cases of skin inflammation, allergic dermatitis, itching and skin lesions resulting from it (Deng et al. 2013). It is currently the only herbal medicine with little complication and its effectiveness has been accepted in the treatment of diaper-induced inflammation (Ness, Davis \& Carey 2013); however, there is the probability of developing contact dermatitis (Reider \& Fritsch 2012). The number of doses and frequency use of the drug do not have a specific instruction; however, in different articles, the frequency of its use varies from three times a day to after each diaper changing (Panahi et al. 2012). 


\section{Chamomile}

Chamomile is one of the herbal medicines used to treat diaper dermatitis, with anti-inflammatory, analgesic and sedative properties (Panahi et al. 2012). Its main components include alpha-bisabolol, bisabolol oxide, chamazulene, and flavonoid. Some people who are allergic to Compositae (Asteraceae) plants like calendula show sensitivity to chamomile (Taheri et al. 2011). Several contact and atopic dermatitis have been reported following chamomile use (Srivastava \& Gupta 2015). No problem has been reported using chamomile in the long run (Srivastava \& Gupta 2015).

\section{Lanolin}

Lanolin or wax is obtained from lamb wool. It is a water-receptive, softening and highly absorbent material used in the basis of special creams for children and medicinal ointments for the treatment of diaper dermatitis and skin protection for children. It regulates hydration of the skin (Allwood 2011) but has an unpleasant odor (2.84). Lanolin has been reported as a common allergen in products containing lanolin (Khalifian, Golden \& Cohen 2017).

\section{Sunflower oil}

Sunflower oil is a mixture of essential oils including oleic acid (omega-9) and linoleic acid (omega-6). The oil contains significant amounts of Vitamin E, sterol, squalene, and aliphatic hydrocarbons (Badouin et al. 2017). It is rapidly absorbed by the skin and a protective effect against dehydration and by having moisturizing and anti-inflammatory properties plays a significant role in skin problems such as diaper dermatitis (Danby et al. 2013). It has been reported that sunflower oil reduced the percentage of sepsis by $41 \%$ in preterm infants. Allergic complications are not unexpected (Macias et al. 2014).

Some studies have been carried out regarding the use of other complementary and traditional treatments such as henna (Keshavarz et al. 2016), the combination of honey, wax and olive oil (El Sakka, Abdulrhman \& Shehata 2013), aloe vera (Panahi et al. 2012), bentonite (Mahmoudi, Adib-Hajbagheri \& Mashaiekhi 2015), clay shampoo (Adib-Hajbagheri, Mahmoudi \& Mashaiekhi 2014), and anti-hemorrhoid ointment (Liu \& Xie 2012), but more studies still need to be done in this topic.

Keshavarz et al. (2016) conducted a randomized tripleblinded study in 2016 to compare the effects of a tradi- tional drug containing henna $25 \%$ and hydrocortisone $1 \%$. In this study, 82 (41 in each group) healthy children under the age of two years suffering from diaper dermatitis were studied and used the drug 3 times a day for 5 days in the area of diaper dermatitis. The results indicated that the intensity of inflammation was significantly higher in the hydrocortisone $1 \%$ group on the $3 \mathrm{rd}$ and $5^{\text {th }}$ days after the onset of intervention $(\mathrm{P}<0.001)$.

In a study by El sakka et al. (2013) to compare the mixture olive oil, honey and wax with nystatin on inflammation caused by diapers in Infants, although there was no significant difference in the score of symptoms in the two groups before the intervention; however, the mixture on day $5(\mathrm{P}=0.04)$ and on day $10(\mathrm{P}=0.001)$ was more effective than nystatin. A double-blind randomized study was conducted in 2012. In this study, 66 healthy children (32 in the aloe vera group and 34 in the calendula group) with dermatitis were studied. Both groups used the drug 3 times a day for 10 days. Recovery was observed in both groups significantly after 10 days $(\mathrm{P}<0.001)$.

The recovery in the calendula group were lower than those in the aloe vera group $(\mathrm{P}=0.001)$ (Panahi et al. 2012). In a random double-blind study with parallel control to compare the effects of Clay Shampoo (CS) and Calendula Ointment (CO) on the improvement of children diaper rash; 60 children (30 in each group) with diaper dermatitis who referred to a clinic were included in the study. According to the study results, 93.3\% of lesions in the CS group improved in the first 6 hours, while this level was $40 \%$ in the CO group $(\mathrm{P}<0.001)$.

In addition, $90 \%$ of children in the CS group and $36.7 \%$ in group $\mathrm{CO}$ completely recovered in the first three days $(\mathrm{P}<0.001)$ (Adib-Hajbagheri, Mahmoudi \& Mashaiekhi 2014). In another random double-blind study with the aim of comparing the effects of topical use of bentonite and calendula creams on diaper dermatitis in children, a total of 100 children with dermatitis (50 children in each group) were included in the study. Six hours after the start of the study, $88 \%$ of the lesions in the bentonite group and $54 \%$ in the calendula group were cured $(\mathrm{P}<0.001)$; the lesions were recovered in $86 \%$ of the bentonite group and $52 \%$ of the calendula group in the first 3 days after treatment $(\mathrm{P}<0.001)$ (Mahmoudi, Adib-Hajbagheri \& Mashaiekhi 2015).

In a study with the aim of investigating the clinical effects of massage therapy with anti-hemorrhoids in the treatment of dermatitis, 44 children ( 22 children in each group) with diaper dermatitis were included in two 
groups of anti-hemorrhoid ointment and hydrochloric ointment. The clinical effect of the anti-hemorrhoid ointment group was clearly better than the hydrochloric ointment group $(\mathrm{P}<0.001)$ (Liu \& Xie 2012). In cases of more severe and resistant infections, oral antibiotics such as amoxicillin clavulanate, clindamycin, cephalexin, and trimethoprim sulfamethoxazole are used in infants (Oranje 2015).

\section{Discussion}

In a reported statistics in the United States, among 2.8 million patients with diaper dermatitis, $75 \%$ of whom were children; drugs of choice included nystatin (27\%), clotrimazole (16\%), combination of nystatin and triamcinolone $(16 \%)$, hydrocortisone $(8 \%)$, and the combination of clotrimazole and betamethasone dipropionate (6\%) (Mack 2010). According to the recommendation of the Food and Drug Administration (FDA) for the treatment of diaper dermatitis associated with secondary infection with Candida albicans, selective treatment with weak non-halogenated corticosteroids such as desonide $0.05 \%$ and hydrocortisone ointment $0.2 \%$, $0.5 \%, 1$, and $2.5 \%$ in combination with topical antifungal agents such as nystatin (Mycostatin), clotrimazole, miconazole, ketoconazole, ciclopirox, or antimicrobial ointment in the diaper area are safe and effective (Telofski et al. 2012).

Meanwhile, manufacturers of the combined products of clotrimazole and betamethasone dipropionate explicitly state that these agents should not be used in children with diaper dermatitis under 2 years old, and precautionary measures are essential in the use of the combination of nystatin and triamcinolone since it contains a medium strength corticosteroid (Mack 2010; Rathi \& D'Souza 2012). In studies conducted between 2013 and 2017, irreversible complications of the corticosteroids have been agreed upon. These side effects may appear locally, such as skin atrophy, abnormal pigmentation, infection, etc. and systemic disorders such as suppression of hypothalamic-pituitary-adrenal axis, Cushing syndrome, retardation and growth retardation in children due to immunosuppression (Jungersted et al. 2011; Liu et al. 2013; Mirshad et al. 2017; Merrill 2015). In recent years, high prevalence of dermatological disorders due to steroids has had a progressive trend with systemic complications (Jungersted et al. 2011).

Moderate and high levels of corticosteroids should not be used to treat diaper dermatitis in children (Liu et al.,2013); the use of longer than 2 weeks of the medication in terms of form and percentage can cause irrepa- rable side effects (Mirshad et al. 2017; Merrill 2015). The infection of dermatitis area with bacteria will add antibacterial antibiotics to the treatment plan. Studies conducted over the years 2010-2018 on antibacterial agents indicate that if they are used inappropriately and for a long time, drug resistance as well as allergic reactions and contact dermatitis are not unexpected (O’Dennell, Gelone \& Safdar 2014).

Fungi are other common microorganisms that usually appear 3 days after the onset of inflammation in the diaper area (Klunk, Domingues \& Wiss 2014). Studies have demonstrated that early diagnosis is a major challenge due to the complexity of clinical profiles, and consequently, increased invasive activity of fungi (Rani et al.2013); this will make it difficult for physicians to choose the type of treatment. According to studies conducted between 2010 and 2017, the use of antifungal treatment in children under the age of 2 years has been the subject of major controversy, and sensitivity reactions have been considered as the most major complications (Hoeger, Stark \& Jost 2010; Iammatteo et al. 2017; Rai et al. 2014; Blanco \& Rossem 2013).

Chemical drugs of modern medicine usually acts faster than herbal drugs, but their prolonged or in some cases, irregular use, unlike herbal medicines, may leave side effects which may be more dangerous than the disease itself (Swain et al. 2018). In addition, the persistent, excessive, and incorrect use of chemical drugs may cause resistance to these drugs (Shenton et al. 2012). It seems that the category of herbal medicines are regarded as the safest category (Swain et al. 2018; Panahi et al. 2012) and no significant adverse complication have been reported until now (Reider \& Fritsch 2012).

However, probable contact dermatitis has been reported (Reider \& Fritsch 2012; Macias et al. 2014). Because of complications of modern therapies and its potential risks, which makes it difficult for the health staff to choose the best treatment method, paying attention to supplementary treatment is not ineffectual. The use of medicinal plants as antibacterial and antiinflammatory drugs is common in Iranian traditional medicine (Panahi et al. 2012).

The effects of plants on human health have been documented for thousands of years (Rai et al. 2014). The persistent popularity of herbal medicines can be attributed to their gradual effects and minimum side effects; nevertheless, the probability of contact dermatitis has been noted for the majority of them, including 
calendula, lanolin, chamomile, honey, aloe vera, sunflowers, and so on (Reider \& Fritsch 2012). Because the complications related to traditional medicine treatments are far less severe than those of chemical drugs and mostly include allergic dermatitis and the like (Panahi et al. 2012), searching new herbal medicines with no side effects in our country seem necessary. They are good choice of treatments available for parents especially for mothers and health care staff at all cultural and educational levels.

In the present study, we tried to present a variety of modern and traditional medicine used in the treatment of diaper dermatitis. The results of the present study indicate that more clinical trials are required to investigate the effects of herbal plants whose complications are not well-documented yet. In addition, conducting further studies to investigate the effectiveness of herbs on secondary fungal infection in the area of dermatitis will likely be a valuable achievement. According to studies conducted around the world, it seems that traditional and herbal treatments can replace modern medicine methods or can be used as complementary therapies along with modern medicine.

\section{Ethical Considerations}

\section{Compliance with ethical guidelines}

There was no ethical principles to be considered in this research.

\section{Funding}

This research did not receive any specific grant from funding agencies in the public, commercial, or not-forprofit sectors.

\section{Conflict of interest}

The authors declared no conflict of interest.

\section{References}

Adib-Hajbaghery, M., Mahmoudi, M. \& Mashaiekhi, M., 2014. Shampoo-clay heals diaper rash faster than calendula officinalis. Nursing and Midwifery Studies, 3(2), p. e14180. [DOI:10.5812/nms.14180]

Al-Faraidy, N. A. \& Al-Natour, S. H., 2010. A forgotten complication of diaper dermatitis: Granuloma gluteale infan- tum. Journal of Family and Community Medicine, 17(2), pp 107-9. [DOI:10.4103/1319-1683.71994] [PMID] [PMCID]

Allwood, M., 2011. Skin care guidelines for infants aged 23-30 weeks' gestation: A review of the literature. Neonatal, Paediatric $\mathcal{E}$ Child Health Nursing, 14(1), p. 20.

Anthony, A. Y., 2016. Equine atopic dermatitis-management (excluding hyposensitization). Paper presented at the $8^{\text {th }}$ World Congress of Veterinary Dermatology, 31 May-4 June 2016, Bordeaux, France.

Babu, G. R., Rao, A. L. \& Rao, J. V., 2014. Development and validation of stability-indicating reverse phase liquid chromatographic method for the assay of desonide in bulk and pharmaceutical formulations. Asian Journal of Research in Chemistry, 7(9), pp. 805-9.

Badouin, H., et al., 2017. The sunflower genome provides insights into oil metabolism, flowering and asterid evolution. Nature, 546(7656), pp. 148-52. [DOI:10.1038/nature22380] [PMID]

Bae, Y. S., et al. 2010. Innovative uses for zinc in dermatology. Dermatologic Clinics, 28(3), pp. 587-97. [DOI:10.1016/j. det.2010.03.006] [PMID]

Ban, L. L. \& Tan, X. L., 2010. Analysis of the utilization of antifungal agents from 2006 to 2008 in our hospital. Evaluation and Analysis of Drug-Use in Hospitals of China, 3, p. 011.

Basha, B., et al., 2015. A comparative study on the efficacy of three galenic preparations for topical use. European Scientific Journal, 11(21), pp. 646-72.

Blanco, D. \& Rossem, K., 2013. A prospective two-year assessment of miconazole resistance in candida SPP with repeated treatment with $0.25 \%$ miconazole nitrate ointment in neonates and infants with moderate to severe diaper dermatitis complicated by cutaneous candidiasis. Pediatric Dermatology, 30(6), pp. 717-24. [DOI:10.1111/pde.12107] [PMID]

Blume-Peytavi, U., et al., 2014. Prevention of diaper dermatitis in infants: A literature review. Pediatric Dermatology, 31(4), pp. 413-29. [DOI:10.1111/pde.12348] [PMID]

Bode, L. G., et al., 2010. Preventing surgical-site infections in nasal carriers of Staphylococcus Aureus. New England Journal of Medicine, 362(1), pp. 9-17. [DOI:10.1056/NEJf Moa0808939] [PMID]

Bodin, M. B., Godoy, G. \& Philips III, J. B., 2015. Topical nystatin for the prevention of catheter-associated candidiasis in ELBW infants. Advances in Neonatal Care, 15(3), pp. 220-4. [DOI:10.1097/ANC.0000000000000170] [PMID]

Camargo Jr, F. B., Gaspar, L. R. \& Maia Campos, P. M., 2011. Skin moisturizing effects of panthenol-based formulations. Journal of Cosmetic Science, 62(4), pp. 361-70. [PMID]

Carvalho, V. O., et al., 2015. Answers to dermatophile. Archives of Disease in Childhood-Education and Practice, 100(4), pp. 224-5. [DOI:10.1136/archdischild-2014-307368a]

Christensen, K. A., et al., 2017. Acupuncture-associated vasovagal response: Revised terminology and hospital experience. Medical Acupuncture, 29(6), 366-76. [DOI:10.1089/ acu.2017.1245] [PMID] [PMCID] 
Crowley, P. D. \& Gallagher, H. C., 2014. Clotrimazole as a pharmaceutical: Past, present and future. Journal of Applied Microbiology, 117(3), pp. 611-7. [DOI:10.1111/jam.12554] [PMID]

Danby, S. G., et al., 2013. Effect of olive and sunflower seed oil on the adult skin barrier: Implications for neonatal skin care. Pediatric Dermatology, 30(1), pp. 42-50. [DOI:10.1111/j.15251470.2012.01865.x] [PMID]

Del Val, I. J., Kontoravdi, C. \& Nagy, J. M., 2010. Towards the implementation of quality by design to the production of therapeutic monoclonal antibodies with desired glycosylation patterns. Biotechnology Progress, 26(6), pp. 1505-27. [DOI:10.1002/btpr.470] [PMID]

Delgado-Charro, M. B. \& Guy, R. H., 2014. Effective use of transdermal drug delivery in children. Advanced Drug Delivery Reviews, 73, pp. 63-82. [DOI:10.1016/j.addr.2013.11.014] [PMID]

Deng, S., et al., 2013. Topical herbal medicine combined with pharmacotherapy for psoriasis: A systematic review and meta-analysis. Archives of Dermatological Research, 305(3), pp. 179-89. [DOI:10.1007/s00403-013-1316-y] [PMID]

Dhingra, D., Parakh, A. \& Ramachandran, S., 2013. Retapamulin: A newer topical antibiotic. Journal of Postgraduate Medicine, 59(2), pp. 127-30. [DOI:10.4103/0022-3859.113842] [PMID]

Eichenfield, L. F., et al., 2014. Guidelines of care for the management of atopic dermatitis: Section 2: Management and treatment of atopic dermatitis with topical therapies. Journal of the American Academy of Dermatology, 71(1), pp. 116-32. [DOI:10.1016/j.jaad.2014.03.023]

El Sakka, A., Abdulrhman, M. \& Shehata, I. H., 2013. Comparison between topical application of honey, bees wax and olive oil propolis extract and nystatin for treatment of diaper dermatitis in infants. International Journal of Pediatrics and Child Health, 1, pp. 39-42.

Gupta, M., et al., 2014. Zinc therapy in dermatology: A review. Dermatology Research and Practice, 2014, p. 709152. [DOI:10.1155/2014/709152] [PMID] [PMCID]

Heise, R., et al., 2012. Dexpanthenol modulates gene expression in skin wound healing in vivo. Skin Pharmacology and Physiology, 25(5), pp. 241-8. [DOI:10.1159/000341144] [PMID]

Heng, Y. K., et al., 2013. Staphylococcus aureus and topical fusidic acid use: Results of a clinical audit on antimicrobial resistance. International Journal of Dermatology, 52(7), pp. 87681 [DOI:10.1111/j.1365-4632.2012.05747.x] [PMID]

Hockenberry, M. J. \& Wilson, D., 2014. Wong's nursing care of infants and children-E-book. Amsterdam: Elsevier Health Sciences.

Hoeger, P. H., Stark, S. \& Jost, G., 2010. Efficacy and safety of two different antifungal pastes in infants with diaper dermatitis: A randomized, controlled study. Journal of the European Academy of Dermatology and Venereology, 24(9), pp. 1094-8. [DOI:10.1111/j.1468-3083.2010.03735.x]

Horii, K. A., 2017. Patient education: Diaper rash in infants and children (Beyond the Basics) [Internet]. viewed 24 Jul 2017, https://www.uptodate.com/contents/diaper-rash-in-infantsand-children-beyond-the-basics

Iammatteo, M., et al., 2017. Severe contact dermatitis due to ethylenediaminedihydrochloride in nystatin cream. The
Journal of Allergy and Clinical Immunology: In Practice, 5(5), pp. 1448-50. [DOI:10.1016/j.jaip.2017.03.006] [PMID]

Inakanti, Y., et al., 2015. Topical corticosteroids: Abuse and misuse. Our Dermatology Online, 6(2), pp. 130-4. [DOI:10.7241/ourd.20152.35]

Jungersted, J. M., et al., 2011. Effects of topical corticosteroid and tacrolimus on ceramides and irritancy to sodium lauryl sulphate in healthy skin. Acta Dermato-Venereologica, 91(3), pp. 290-4. [DOI:10.2340/00015555-1064] [PMID]

Keshavarz, A., et al., 2016. Efficacy of traditional medicine product henna and hydrocortisone on diaper dermatitis in infants. Iranian Red Crescent Medical Journal, 18(5), p. e24809. [DOI:10.5812/ircmj.24809] [PMID] [PMCID]

Khalifian, S., Golden, W. C. \& Cohen, B. A., 2017. Skin care practices in newborn nurseries and mother-baby units in Maryland. Journal of Perinatology, 37(6), pp. 615-21. [DOI:10.1038/jp.2016.226] [PMID]

Kharazmi, S. A., et al., 2012. Management of afebrile neonates with skin and soft tissue infections in the pediatric emergency department. Pediatric Emergency Care, 28(10), pp. 1013-6. [DOI:10.1097/PEC.0b013e31826caaac] [PMID]

Klunk, C., Domingues, E. \& Wiss, K., 2014. An update on diaper dermatitis. Clinics in Dermatology, 32(4), pp. 477-87. [DOI:10.1016/j.clindermatol.2014.02.003] [PMID]

Kuller, J. M., 2016. Infant skin care products: What are the issues. Advances in Neonatal Care, 16, pp. S3-12. [DOI:10.1097/ ANC.0000000000000341] [PMID]

Liu, C., et al., 2011. Clinical practice guidelines by the Infectious Diseases Society of America for the treatment of methicillin-resistant Staphylococcus aureus infections in adults and children. Clinical Infectious Diseases, 52(3), pp. e18-e55. [DOI:10.1093/cid/ciq146] [PMID]

Liu, D., et al., 2013. A practical guide to the monitoring and management of the complications of systemic corticosteroid therapy. Allergy, Asthma \& Clinical Immunology, 9(1), p. 30. [DOI:10.1186/1710-1492-9-30] [PMID] [PMCID]

Liu, X. \& Xie, Y., 2012. Clinical curative effect of mayinglong musk hemorrhoids ointment in treatment of infant diaper dermatitis. China Knowledge Infrastructure Engineering, 10(5), p. 82.

Macias, M. L., et al., 2014. Identification of helianthus annuus allergens in subjects with allergy to sunflower. Clinical and Translational Allergy, 4(2), p. P14. [DOI:10.1186/2045-7022-4S2-P14] [PMCID]

Mack, K. H., 2010. The best practice guideline for the treatment of pediatric diaper dermatitis [PhD dissertation]. Columbia: University of South Carolina.

Mahmoudi, M., Adib-Hajbaghery, M. \& Mashaiekhi, M., 2015. Comparing the effects of Bentonite \& Calendula on the improvement of infantile diaper dermatitis: A randomized controlled trial. The Indian Journal of Medical Research, 142(6), pp. 742-6. [DOI:10.4103/0971-5916.174567] [PMID] [PMCID]

McQuestion, M., 2011. Evidence-based skin care management in radiation therapy: Clinical update. Seminars in Oncology Nursing, 27(2), pp. e1-e17. [DOI:10.1016/j.soncn.2011.02.009] [PMID] 
Merrill, L., 2015. Prevention, treatment and parent education for diaper dermatitis. Nursing for Women's Health, 19(4), pp. 324-37. [DOI:10.1111/1751-486X.12218] [PMID]

Mirshad, P. V., et al., 2017. Prescription audit of corticosteroid usage in the department of dermatology at a tertiary care teaching hospital. International Journal of Basic \& Clinical Pharmacology, 2(4), pp. 411-3. [DOI:10.5455/2319-2003. ijbcp20130813]

Moody, M. N., Morrison, L. K. \& Tyring, S. K., 2010. Retapamulin: What is the role of this topical antimicrobial in the treatment of bacterial infections in atopic dermatitis. Skin Therapy Letter, 15(1), pp. 1-4. [PMID]

Mooney, E., et al., 2015. Adverse effects of topical corticosteroids in paediatric eczema: Australasian consensus statement. Australasian Journal of Dermatology, 56(4), pp. 241-51. [DOI:10.1111/ajd.12313] [PMID]

Ness, M. J., Davis, D. M. \& Carey, W. A., 2013. Neonatal skin care: A concise review. International Journal of Dermatology, 52(1), pp. 14-22. [DOI:10.1111/j.1365-4632.2012.05687.x] [PMID]

O’Dennell, J. A., Gelone, S. P. \& Safdar A., 2014. Topical antibacterials. In J. E. Bennett., R. Dolin. \& M. J. Blaser (eds.) Principles and Practice of Infectious Diseases. Philadelphia: Saunders.

Oranje, A. P., 2015. Recent developments in the management of common childhood skin infections. Journal of Infection, 71, pp. S76-9. [DOI:10.1016/j.jinf.2015.04.030] [PMID]

Panahi, Y., et al., 2012. A randomized comparative trial on the therapeutic efficacy of topical aloe vera and Calendula officinalis on diaper dermatitis in children. The Scientific World Journal, 2012, p. 810234. [DOI:10.1100/2012/810234] [PMID] [PMCID]

Posadzki, P., Watson, L. \& Ernst, E., 2013. Herb-drug interactions: An overview of systematic reviews. British Journal of Clinical Pharmacology, 75(3), pp. 603-18 [DOI:10.1111/j.13652125.2012.04350.x] [PMID] [PMCID]

Qian, J., et al., 2012. Size-resolved emission rates of airborne bacteria and fungi in an occupied classroom. Indoor Air, 22(4), pp. 339-51. [DOI:10.1111/j.1600-0668.2012.00769.x] [PMID] [PMCID]

Rai, V. K., et al., 2014. Development of cellulosic polymer based gel of novel ternary mixture of miconazole nitrate for buccal delivery. Carbohydrate Polymers, 103, pp. 126-33. [DOI:10.1016/j.carbpol.2013.12.019] [PMID]

Rani, N., et al., 2013. Imidazoles as potential antifungal agents: A review. Mini Reviews in Medicinal Chemistry, 13(11), pp. 1626-55. [DOI:10.2174/13895575113139990069] [PMID]

Rasu, R. S., et al., 2013. Assessing chronic pain treatment practices and evaluating adherence to chronic pain clinical guidelines in outpatient practices in the United States. The Journal of Pain, 14(6), pp. 568-78. [DOI:10.1016/j. jpain.2013.01.425] [PMID]

Rathi, S. K. \& D'Souza, P., 2012. Rational and ethical use of topical corticosteroids based on safety and efficacy. Indian Journal of Dermatology, 57(4), p. 251 [DOI:10.4103/00195154.97655] [PMID] [PMCID]

Reider, N. \& Fritsch, P. O., 2012. Other eczematous eruptions. In: R. P. Rapini., J. L. Jorizzo. \& J. L. Bolognia (eds), Dermatology. Amsterdam: Elsevier.
Schram, M. E., et al., 2011. Off-label use of azathioprine in dermatology: A systematic review. Archives of Dermatology, 147(4), pp. 474-88. [DOI:10.1001/archdermatol.2011.79] [PMID]

Schwartz, R. A. \& Al Mutairi, N., 2010. Topical antibiotics in dermatology: An update. Global Journal of Dermatology \& Venereology, 17(1), pp. 1-19.

Segura-Bedmar, I., Martinez, P. \& de Pablo-Sánchez, C., 2011. Using a shallow linguistic kernel for drug-drug interaction extraction. Journal of Biomedical Informatics, 44(5), pp. 789804. [DOI:10.1016/j.jbi.2011.04.005] [PMID]

Shen, T. \& Huang, S., 2016. Repositioning the old fungicide ciclopirox for new medical uses. Current Pharmaceutical Design, 22(28), pp. 4443-50. [DOI:10.2174/138161282266616053 0151209] [PMID]

Shenton, M. E., et al., 2012. A review of magnetic resonance imaging and diffusion tensor imaging findings in mild traumatic brain injury. Brain Imaging and Behavior, 6(2), pp. 13792. [DOI:10.1007/s11682-012-9156-5] [PMID] [PMCID]

Speight, J. G., 2014. The chemistry and technology of petroleum. Boca Raton, Florida: CRC press.

Srivastava, J. K. \& Gupta, S., 2015. Chamomile: A herbal agent for treatment of diseases of the elderly. In R. R. Watson (ed.), Foods and dietary supplements in the prevention and treatment of disease in older adults. Amsterdam: Elsevier. [DOI:10.1016/ B978-0-12-418680-4.00018-X]

Stamatas, G. N. \& Tierney, N. K., 2014. Diaper dermatitis: Etiology, manifestations, prevention, and management. Pediatric Dermatology, 31(1), pp. 1-7. [DOI:10.1111/pde.12245] [PMID]

Swain, S. K., et al., 2018. Povidone iodine soaked gelfoam for the treatment of recalcitrant otomycosis: Our experiences at a tertiary care teaching hospital of eastern India. Journal de Mycologie Medicale, 28(1), pp. 122-7. [DOI:10.1016/j.mycmed.2017.11.006] [PMID]

Taheri, J. B., et al., 2011. Herbs in dentistry. International Dental Journal, 61(6), pp. 287-96. [DOI:10.1111/j.1875595X.2011.00064.x] [PMID]

Tamblyn, R., et al., 2012. The effectiveness of a new generation of computerized drug alerts in reducing the risk of injury from drug side effects: A cluster randomized trial. Journal of the American Medical Informatics Association, 19(4), pp. 635-43. [DOI:10.1136/amiajnl-2011-000609] [PMID] [PMCID]

Tan, X., et al., 2012. Topical drug delivery systems in dermatology: A review of patient adherence issues. Expert Opinion on Drug Delivery, 9(10), 1263-71. [DOI:10.1517/17425247.201 2.711756] [PMID]

Telofski, L. S., et al., 2012. The infant skin barrier: Can we preserve, protect, and enhance the barrier. Dermatology Research and Practice, 2012, p. 198789. [DOI:10.1155/2012/198789] [PMID] [PMCID]

Verma, P. \& Pathak, K., 2012. Nanosizedethanolic vesicles loaded with econazole nitrate for the treatment of deep fungal infections through topical gel formulation. Nanomedicine: Nanotechnology, Biology and Medicine, 8(4), pp. 489-96. [DOI:10.1016/j.nano.2011.07.004] [PMID]

Visscher, M. O., et al., 2015. Newborn infant skin: Physiology, development, and care. Clinics in Dermatology, 33(3), pp. 271-80. [DOI:10.1016/j.clindermatol.2014.12.003] [PMID] 
Weinberg, J. M. \& Tyring, S. K., 2010. Retapamulin: An antibacterial with a novel mode of action in an age of emerging resistance to Staphylococcus aureus. Journal of Drugs in Dermatology, 9(10), pp. 1198-204. [PMID]

Zannolli, R., et al., 2012. A randomized trial of oral betamethasone to reduce ataxia symptoms in ataxia telangiectasia. Movement Disorders, 27(10), pp. 1312-6. [DOI:10.1002/ mds.25126] [PMID]

Zitás, É. \& Mészáros, J., 2016. The most common childhood skin diseases. Our Dermatol Online, 7(2), pp. 213-8. [DOI:10.7241/ourd.20162.59]

Zumla, A., 2010. Mandell, Douglas, and Bennett's principles and practice of infectious diseases. The Lancet Infectious Diseases, 10(5), pp. 303-4. [DOI:10.1016/S1473-3099(10)70089-X] 
February 2018. Volume 4. Number 1

Client-Centered Nursing Care 